\title{
Chapter 10 \\ Approaching Proof in the Classroom Through the Logic of Inquiry
}

\author{
Ferdinando Arzarello and Carlotta Soldano
}

\begin{abstract}
The paper analyses a basic gap, highlighted by most of the literature concerning the teaching of proofs, namely, the distance between students' argumentative and proving processes. The analysis is developed from both epistemological and cognitive standpoints: it critiques the Toulmin model of reasoning and introduces a new model, the Logic of Inquiry of Hintikka, more suitable for bridging this gap. An example of didactical activity within Dynamic Geometry Environments is sketched in order to present a concrete illustration of this approach and to show the pedagogical effectiveness of the model.
\end{abstract}

Keywords Proof - Logic of inquiry - Argumentation - Dynamic geometry environments

\subsection{Introduction}

In their wonderful book Anschauliche Geometrie, Hilbert and Cohn-Vossen (1932) wrote $^{1}$ :

In mathematics, as in all scientific research, we find two tendencies: the tendency to abstraction - it seeks to work out (herauszuarbeiten) the logical points of view from the manifold material and bring this into systematic connection — and the other tendency, that

\footnotetext{
${ }^{1}$ In der Mathematik wie in aller wissenschaftlichen Forschung treffen wir zweierlei Tendenzen an: die Tendenz zur Abstraktion - sie sucht die logischen Gesichtspunkte aus dem vielfältigen Material herauszuarbeiten und dieses in systematischen Zusammenhang zu bringen - und die andere Tendenz, die der Anschaulichkeit, die vielmehr auf ein lebendiges Erfassen der Gegenstände und ihre inhaltlichen Beziehungen ausgeht.
}

\section{F. Arzarello $(\square)$}

Dipartimento di Matematica "Giuseppe Peano", Università di Torino, Turin, Italy

e-mail: ferdinando.arzarello@unito.it

C. Soldano

Dipartimento di Filosofia e Scienze dell'educazione, Università di Torino, Turin, Italy

e-mail: carlotta.soldano@unito.com 
of intuitive understanding (Anschaulichkeit), which rather gets (ausgeht) the object and its substantive relationships from a living grasping. (p. XVII: translation of the authors).

These two aspects of mathematics are also crucial for its teaching and present a basic problem: how to suitably cultivate both aspects in the classroom? And more specifically, which roles should mathematical proofs and intuitive argumentations have in its teaching-learning activities?

This is an old controversial issue (e.g., see Fawcett 1938), and, from terminology to more substantial content, things appear very mazy in the literature. For example, in the most recent Compendium, the chapter dedicated to research on the teaching and learning of proofs (Stylianides et al. 2017), the authors report "the lack of consensus about what proof means in mathematics education research" (p. 238). However, the meaning of proof is not uniform, on the contrary there is a large consensus about the fact that an unattainable barrier seems to exist, which makes it difficult for students (and sometimes also for teachers: see Key findings by Stylianides et al. 2017, pp. 245-246) to grasp the formal aspects of proofs.

Teaching proofs seems to require that students (and teachers) acquire a new, not 'natural' basis for their beliefs. It is the same general notion of formal reasoning that creates this wall and inhibits understanding. An example is given by the following test, taken from the book by Lolli (2005), submitted to students (at secondary and university level) and also to teachers, which always gives the same results. Three syllogisms A, B, C are given one at a time (see Table 10.1) and people are asked each time to judge if they are correct or not:

Try it yourself before continuing!

A very high percentage of participants give different answers to them: generally, people judge A as correct, $\mathrm{B}$ as incorrect and both judgments are made at once. A lower percentage say that $\mathrm{C}$ is incorrect, but after some time (some after having checked with the Euler-Venn diagrams); in this case, there is also a considerable number of not-answers. However, A, B, C are instantiations of the same (incorrect) syllogism! This performance represents a typical obstacle that students must overcome in their attempt to grasp formal reasoning at a very basic level: possibly, some of the pitfalls recorded in the literature, such as the incapability of students and teachers to distinguish between proofs and invalid arguments (see Stylianides et al. 2017, pp. 242-243; Selden and Selden 2003), have a common basic cognitive root, which can be active in different (negative) ways according to the context, the representation of the situation, etc.; also the corresponding formal statements do not provide enough support for subjects' understanding. We call it the basic gap between (formal) proofs and (intuitive) arguments: whatever definition of proof is

Table 10.1 Examples of syllogism

\begin{tabular}{l|l|l}
\hline A & B & C \\
\hline No right-angled triangle is equilateral; & No dog is a ruminant & No S is M \\
\hline $\begin{array}{l}\text { Some isosceles triangles are } \\
\text { equilateral; }\end{array}$ & $\begin{array}{l}\text { Some quadrupeds are } \\
\text { ruminants }\end{array}$ & Some P are M \\
$\begin{array}{l}\text { Therefore, some right-angled triangles } \\
\text { are not isosceles }\end{array}$ & $\begin{array}{l}\text { Therefore, some dogs are } \\
\text { not quadrupeds }\end{array}$ & $\begin{array}{l}\text { Therefore, some S } \\
\text { are not P }\end{array}$ \\
\hline
\end{tabular}


given, even the most open and inclusive, the basic gap is behind it and can make any approach to the proof in the classroom problematic. A general pedagogical consequence is that "the place of proof in typical $\mathrm{K}-12$ school mathematics classroom practice [...] is marginal" (Stylianides et al. 2017, p. 251).

For this reason, we think that deepening the analysis of the basic gap is the primary goal of any study focused on the teaching/learning of proof.

In next sections we approach the basic gap from two points of view:

- cognitive: considering some pieces of research that introduce the notion of cognitive (dis-) continuity between argumentation and proof and picture the basic gap as it can arise in the classroom;

- epistemic: considering the logic of inquiry (LI) in the sense of J. Hintikka, which in a sense reverses the ways deductive concatenations are developed according to the logical rules of reasoning.

Then we illustrate an example of didactic activity, developed jointly by Arzarello and Soldano for her Ph.D. work (Soldano 2017), based on LI and aimed at reducing the basic gap in the classroom through appropriate didactic engineering within a technological environment.

The chapter concludes showing that sometimes the discontinuity thesis is based on a series of misunderstandings about what is to be assumed as proving activity. On the contrary, the two aspects (arguments and proofs) can be integrated with each other at a certain grade from both an epistemic and a cognitive point of view.

\subsection{Argumentations and Proofs: Education to Rationality as a Learning Goal in Secondary School}

As we observed in the introduction, the literature pertaining to the teaching and learning of proofs often highlights a tension, not to say a contrast, between the formal aspects of proofs, subject to precise logical and textual rules, on the one hand, and the more informal arguments, on the other, which on their side may correspond to creative problem solving processes and to the understanding of mathematical concepts within the classroom horizon of knowledge. The latter do not always appear easily reducible or able to be integrated coherently with the former. The concrete result of these difficulties is that, simplifying a little, we find two opposing positions on the problem of the relationship between proofs and argumentation in both epistemological and educational research.

From the epistemic side, ${ }^{2}$ they are outlined by Hintikka (1999), to whose contributions we shall return:

\footnotetext{
${ }^{2}$ In general, we use the adjective 'epistemological' to indicate the knowledge of the methods of the sciences and of the principles according to which science constructs itself; instead we use the
} 
The main currently unsolved problem in the theory of argumentation concerns the function of logic in argumentation and reasoning. The traditional view simply identified logic with the theory of reasoning. This view is still being echoed in older textbooks of formal logic. In a different variant, the same view is even codified in the ordinary usage of words such as 'logic', 'deduction', 'inference', etc. For each actual occurrence of these terms in textbooks of formal logic, there are hundreds of uses of the same idioms to describe the feats of real or fictional detectives. [...]

Needless to say, this traditional conception of logic and deduction has been rejected with a rare unanimity by recent theorists of human reasoning and argumentation. It is widely assumed that the truths of formal logic are mere tautologies or analytical truths without substantial content and hence incapable of sustaining any inferences leading to new and even surprising discoveries, as the detections of sleuths like Sherlock Holmes or Nero Wolfe were supposed to lead. (p. 25)

From the educational side, we also find two possible approaches. Some studies illustrate a substantial didactical discontinuity between argumentations and proofs, highlighting a jump between the two (which we have called the basic gap). Some scholars highlight a form of cognitive discontinuity between them; others highlight an epistemic discontinuity between the respective statuses of knowledge; often the two forms of discontinuity are both stressed in the same research. In any case, all of them say that it is very difficult to find an effective way of teaching and learning of proofs in the classroom. As examples, see the research studies touched upon in their chapter in the Compendium by Stylianides et al. (2017), and others, like those of Balacheff (1987), Duval (1991), and Thompson et al. (2012). However, in the panorama of the didactic research on proof, we also find opposite positions. The studies by Boero et al. (1996), Garuti et al. (1996, 1998), Mariotti (2006), Pedemonte (2007), Baccaglini-Frank and Mariotti (2010) and others (see for example the discussion and the related bibliography in the papers by Boero et al. 2010; Guala and Boero 2017) highlight the possibility of forms of cognitive continuity between the construction of a conjecture and the construction of the proof, which they call cognitive unity:

During a problem-solving process, an argumentation activity is usually developed to produce a conjecture. The hypothesis of cognitive unity is that in some cases this argumentation can be used by the student in the construction of proof by organising in a logical chain some of the previously produced arguments. (Pedemonte 2007, p. 24)

The studies mentioned above show that proof is more 'accessible' to students if an argumentation activity is developed for the construction of a conjecture and, conversely, the construction of proof is more difficult if such a cognitive unity is not achieved.

adjective 'epistemic' to indicate the programs of scientific investigation, and the related theories, pursued and implemented by different schools and authors. In other words, 'epistemological' refers to the subject who studies epistemic matters, whereas 'epistemic' merely refers to knowledge, justification and belief. The distinction between 'ontics' and 'ontology' is proper to the Continental philosophy (contrasted with the Analytical one); the difference was discussed by Heidegger (1927): ontic is what makes something what it is; while ontological refers to one's own first-person, subjective, phenomenological experience of being. 
Other research shows that the Dynamic Geometry Environments, DGE, (e.g. Cabri Géomètre, Geogebra, Sketchpad, etc.) can support forms of cognitive continuity, at least in the case of elementary geometry (Arzarello et al. 2012: see the discussion about abductions in the final section).

In any case, the pedagogical problem of how to teach/learn proof at school is still open, provided that it is a teaching goal in the school (e.g. it is so in the Italian $\mathrm{Licei}^{3}$ ). It requires the taking of a position with respect to the previous dilemmas (be they epistemic, cognitive, or both) on the value of the logical deductions with respect to argumentations.

\subsection{The Theoretical Basis of Our Proposal}

In the chapter we continually use the terms argumentation and proof. Clarifying their meaning and mutual relationships for learning purposes is among the objectives of this contribution. To orient the reader, we give now two definitions and will discuss the reasons why we have chosen this formulation.

Following Toulmin (1958, 1974), Toulmin et al. (1984), we use the term argumentation (or reasoning) to refer to a text made of one or more concatenated argumentative steps. An argumentative step is identifiable through the presence of a Fact, a Claim and a Warrant that justifies the validity (possibly with a certain degree of probability) of the Claim, because of the Fact (Fig. 10.1).

The Warrant can explicitly or implicitly refer to a set of knowledge, principles, etc. possibly organized in the system (Backing) on which the Warrant is based. Sometimes in the argumentation there are exceptions (Rebuttal) according to which the Claim does not follow from the data under the Warrant. Figure 10.2 exemplifies this situation.

For the notion of proof, we instead refer to Rav (1999): "Proofs are the mathematician's way to display the mathematical machinery for solving problems and to justify that a proposed solution to a problem is indeed a solution" (p. 13).

It should be noted that often in the literature and in the practice of teaching some people tend to identify proofs with derivations (purely syntactic objects); but a proof is never reducible to this specific aspect only (see Rav 1999, p. 12 and the comments on the so called DTP model, definition-theorem-proof, by Thurston 1994).

To deepen the analysis on the theme continuity-discontinuity between arguments and proofs we refer to two theoretical models. First of all, we consider Toulmin's

\footnotetext{
${ }^{3}$ The Italian curriculum identifies five main learning areas, one of which is the logical-argumentative one. Its main competencies are described as follows: "Knowing how to support one's own thesis and how to listen and critically evaluate the arguments of others. Acquiring the habit of reasoning with logical rigor, of identifying problems and their possible solutions. Being able to read and to critically interpret the contents of different forms of communication."
} 
Fig. 10.1 Toulmin's model (I)

Fig. 10.2 Toulmin model (II)

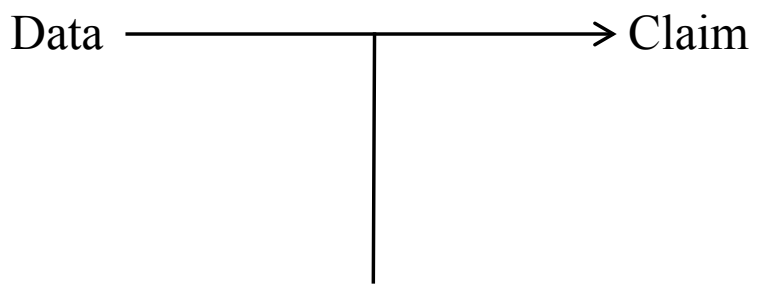

Warrant

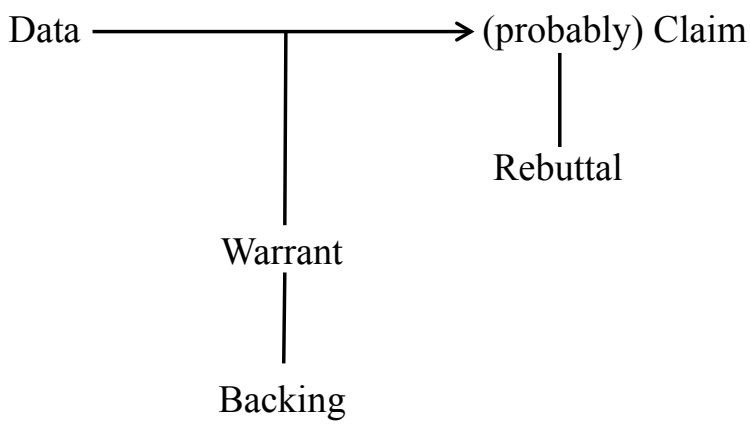

model, sketched above, since it is widely used in mathematics education research (for example, by Boero et al. 1996, 2010; Boero 2011, and by Knipping and Reid 2015). Its critical analysis from an epistemic point of view led us to consider another model: the Logic of Inquiry by Hintikka (logician). For space reasons, we cannot introduce a third important model, which is due to an adaptation (Boero and Planas 2014; Guala and Boero 2017) of the construct of rationality by Habermas (we invite readers with an interest in the discursive practices related to proofs to consult these references).

\subsubsection{The Model of Stephen E. Toulmin}

We have already introduced the Toulmin model for our definition of argumentation. He calls his model "substantial" and "practical" in opposition to the "analytical" and "theoretical" character of the syllogism, which for him fully represents logical deduction.

For Toulmin, an argumentation makes sense only if it is contextualized: the English scholar typically thinks of it as a discourse that takes place between two people, in disagreement about the proposed statement; in this way, one of them disputes the Claim, and the other, who made the initial affirmation, tries to justify it by giving increasing Warrants with their Backings. The model is inspired by legal practice and this is the reason why Toulmin calls it jurisprudential (Toulmin 1958, 
pp. 41-43): in fact, the five components of the arguments assume their full meaning in a debate that takes place in a courtroom during the discussion of a specific legal case. The goal is to convince the adversary, not the search/explanation of the truth, which is instead the goal of scientific argument, in particular in mathematics. The full meaning of the Toulmin model is therefore constituted by the intertwining of the two components:

(a) the structure (Claim-Fact-Warrant-Backing-Rebuttal)

(b) the context in which the argument takes place.

The structure of part (a) makes sense only if modeled by the dynamic process of part (b) and its elements are seen according to this perspective (Zarębski 2009).

Unfortunately, most of the literature that uses Toulmin's model in mathematical education somewhat neglects the analysis of the relationships between the two components (a) and (b). This is not by chance. A first reason is that the jurisprudential model is quite different from that of scientific investigation, mathematics in particular: the distinction between Warrant and Backing is important in the jurisprudential model but it does not appear to fit so well with the mathematical field. Toulmin (1975) illustrated "how the sort of backing called for by our arguments varies from one field of argument to another" (p. 97). For example, the three different warrants 'A whale will be a mammal', 'A Bermudan will be a Briton', 'A Saudi Arab will be a Muslim' rely on different backings: the first warrant is supported by referring it to a taxonomic classification system, the second by referring to the rules governing the nationality of British colonies (at the time when Toulmin wrote), and the third to the statistics recording the distribution of religious faiths among people of different nationalities. The relative backings therefore refer to texts of Zoology, to the English laws in effect in a certain year, to statistical data collected following certain protocols.

A second reason is that the model in all the exemplifications refers exclusively to the forms of syllogistic reasoning as an example of analytical reasoning: this is a very serious limitation of its use in the analysis of mathematical reasoning, which, as it is known, cannot be reduced to syllogisms alone (Börger et al. 1997). This has important consequences for the structure of mathematical and scientific arguments in general, as we now illustrate with an example.

It is well known that in mathematics we have many sentences like "for all $x$, there exists a $y$ such that...". $\forall \exists$-form). A typical example is the continuity of a function at a point. Let's consider the function $f(x)=x^{2}$ and suppose we want to show that it is continuous in $x_{0}=1$. To show this to her/his students, a teacher can imagine two opponents, the first (C) supporting the truth of the statement, and the antagonist (A) denying it. ${ }^{4}$ The scenario shows students that it is impossible for A to be right: in fact even if $\mathrm{A}$ chooses a very small $\varepsilon$, say $\varepsilon=0.001, \mathrm{C}$ can

\footnotetext{
${ }^{4}$ It is something similar to the spirit of the jurisprudential model, even if this aspect curiously does not appear in the mathematical education texts that refer to this model.
} 
consequently find an appropriate $\delta$, say $\delta=0.0001$, which satisfies the required inequality.

Of course, we can ask what the Warrant of this argumentation is, which consists of a process of generalization from the generic example given by the pair $\left(\varepsilon_{0}, \delta_{0}\right)$, where $\varepsilon_{0}, \delta_{0}$ are the data, to the General Warrant that supports the Claim, possibly basing the warrant on some definitions and Analysis theorems (Backing). However, the crucial step in this dynamic reasoning consists in grasping and possibly making explicit in the discourse the functional dependence of $\delta$ on $\varepsilon$, as a result of the interactions between $C$ and A. Toulmin's model does not seem able to explain these functional aspects, even if it can explain other aspects of the argument, such as the transition from a generic example to a general statement, its relationship with the theory that underpins the argument itself, etc.

Our conjecture is that the great idea of the jurisprudential method is like a good wine put into an inadequate barrel, that is into the ancient syllogistic scheme, to which every relational and functional aspect was extraneous. This is precisely the great step taken by modern logic thanks above all to Frege, as explained in his Begriffshrift (Ideography 1879). It is instructive to quote Frege on the new method, since he clearly indicates the relevance of a functional approach to what he defines as "a linguistic formula for pure thought, modelled on that of arithmetic", that is, for the new language of mathematical logic:

If in an expression [...] a simple or compound sign has one or more occurrences and if we consider that sign as substitutable in all or some of these occurrences by something else (but everywhere by the same thing), then we call that part that remains invariant in the expression a function, and the substitutable part is the argument of the function ${ }^{5}$. (p. 16: translation by the authors)

The Toulmin model highlights an essential characteristic of scientific arguments, namely their dynamical and dialogical characteristics, but it is not suitable to capture the modern development of scientific investigation in its entirety, as it does not allow for the consideration of the functional dependence between variables and parameters, which are so frequent in mathematical discourses and constitute the fundamental objective of the modern scientific method.

Therefore, in order that the characteristics proposed in part (b) of the Toulmin model be valid for scientific investigation and in particular for mathematics, it is necessary to expand the structural part of its model by entering more dynamically and deeply into the fundamental part of its relationship (Fact-Claim-Warrant).

This was done in a substantial way by Hintikka with his Logic of Inquiry (LI), which follows a path of epistemic continuity between arguments and proofs. We introduce LI briefly in the next section, postponing some further comments on it until the final discussion.

\footnotetext{
${ }^{5}$ Wenn in einem Ausdrucke [...] ein einfaches oder zusammengesetztes Zeichen an einer oder an mehren Stellen vorkommt, und wir denken es an allen oder einigen dieser Stellen durch Anderes, überall aber durch Dasselbe ersetzbar, so nennen wir den hierbei unveränderlich erscheinenden Theil des Ausdruckes Function, den ersetzbaren ihr Argument.
} 


\subsubsection{The Logic of Inquiry by Jaako Hintikka}

Here we come back to the theme of epistemic tension existing between argumentation and proof in order to deepen the analysis of this complex relationship, the clarification of which is crucial for setting up a correct teaching program in mathematics, in particular for mathematical proofs. In this section we introduce the model of argumentation that results from Hintikka's Logic of Inquiry (LI).

Hintikka was a Finnish philosopher and a professor of logic in Helsinki, Stanford and Boston. He introduced the LI to overcome the static approach to reasoning represented by the usual mathematical logic, and thus his approach was in tune with Toulmin's dynamic model. However, he developed critical positions with respect to the English linguist (Hintikka 1999, p. 9ff.). Since his work is not as well known, we briefly summarize his model and its relationships with that of Toulmin. For this purpose, we refer to his many publications in which he exhibits LI and which are the result of more than thirty years of research done by himself and by his school. We draw particular attention to the following works: the volumes by Hintikka in 1998 and 1999; and two chapters in volumes in 1997, pp. 13-33; and by Hintikka and Sandu (1997, pp. 415-466).

To enter into the merit of the interweaving of logical deductions and arguments, we follow Hintikka in the analysis of a very well-known type of reasoning-argumentation, that is, the so-called 'deductive method' of Sherlock Holmes. As Hintikka himself mentions, Sherlock Holmes is the character who best embodies the characteristics of the lucid thinker: in fact, he makes the deductive method the basis of his investigations.

The method of Holmes is admirably exemplified in the story, Silver Blaze, which Hintikka (1999, p. 31) takes as a typical example of logical reasoning, in particular in the "curious incident of the dog in the night". The famous racing horse Silver Blaze is stolen from the stable in the middle of the night and the next morning his coach is found dead in the heathland, having been brutally murdered. Many suspects emerge but no one knows what really happened. Here is the conversation that takes place between Inspector Gregory and Sherlock Holmes:

Isp. Gregory: Is there any other point to which you would wish to draw my attention?

S. H.: To the curious incident of the dog in the night-time.

Isp. Greogory: The dog did nothing in the night-time.

S. H.: That was the curious episode.

According to Hintikka, the brilliant deductions of the English detective can be rewritten as a succession of questions and answers. To explain this, in fact, he rewrites the dialogue in this form, in which Sherlock Holmes is in fact asking three questions to witnesses or to Inspector Gregory, who answer accordingly (inquiring process):

a. Was there a watchdog in the stables when the horse disappeared?

Yes, we have been told that there was. 
b. Did the dog bark when the horse was stolen?

No, no one woke up, not even the stable-boys in the loft ("That was the curious incident").

c. Who is it that a trained watchdog does not bark at in the middle of the night?

His owner, the stable-master, of course. Hence it was the stable-master himself who stole the horse... Elementary, my dear Watson.

The answers given to questions are known or observed facts that help Holmes unravel the mystery of the horse's disappearance.

Holmes' way of reasoning is based on what Hintikka calls the interrogative model, to which we shall return. Holmes' deductive arguments are a transposition of the inquiring process into a deductive one, namely into the following logical chain (Fig. 10.3):

1. There was a watchdog in the stable at night

2. The dog did not bark when the horse was stolen

3. A trained watchdog doesn't bark only at its owner

4. Hence the thief was the owner.

However, the deductive transposition alone does not fully capture the sense of Sherlock Holmes' reasoning, which revolves around the "curious incident of the dog that did not bark". The dog that did not bark is the element of novelty in the argument (which for this reason arouses the astonished comment of the inspector): this move, consisting of the introduction of a new individual in an argument, differentiates the reasoning of Holmes from standard deductive reasoning, where every deductive move is made starting from the individuals explicitly or implicitly presented in the premises. $^{6}$

In fact, LI is an example of epistemic logic, ${ }^{7}$ which allows for the rendering of both processes (inquiring and deductive) in a unitary frame.

Beyond the technical aspects, to which we shall come in the final Discussion, there are three which are the most fundamental and deeply intertwined characteristics that characterize the LI model:

i. the dialectic between questions and answers;

ii. the deep link with game theory;

iii. the functional interpretation of connectives and quantifiers.

We have seen (i) in the example of S.H. (questions a, b, c): "asking a question and receiving an answer (that is, an interrogative move) is radically different from a step in a logical deduction (logical inference move)." (Hintikka 1999, p. x). For (ii),

\footnotetext{
${ }^{6}$ For example, the existential instantiation is a move that does not add a substantially new element, insofar the statement $\exists x A(x)$ is replaced by the statement $A(b)$, where $b$ is a new individual term, which precisely serves as a generic individual for the statement $A(x)$. Term $b$ is implicitly present in preamble $\exists x A(x)$. We further enter into this issue in the final Discussion.

${ }^{7}$ See: https://plato.stanford.edu/entries/logic-epistemic/.
} 
Fig. 10.3 The reasoning of Sherlock Holmes

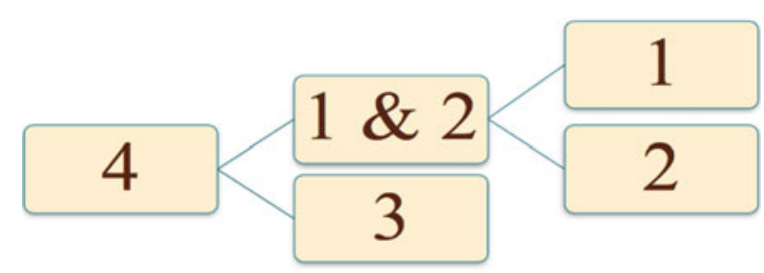

fHintikka explains the complexity of LI through the fundamental distinction between two types of "rules" that govern it, as in a chess game (pp. 2-3):

definitory rules (framing the deductive steps);

strategic principles (generating the inquiry steps).

It is through an appropriate combination of the two that the "game of logic", as Hintikka calls it, can be developed: they are like the two sides of the same coin and the issue of game is more than a metaphor. On the one hand, the canonical version of game theory has a specific logical sense in that it extends the framework of deductive logic to a wider coherent theoretical context. On the other hand, its model interpreted according to the LI captures the dynamics of a rational theory of discovery, so it is relevant in teaching and learning mathematics as well as in research.

For (iii), it is exactly the interpretation through game theory that the functional interpretation of mathematical sentences (illustrated above with the $x y$ statement about continuity) acquires its full sense. Commenting on the way Weierstrass explains the concept of limit, Hintikka explains this point in the same words used by Stewart (1992, pp. 105-108):

A function $f(x)$ approaches a limit $\mathrm{L}$ as $\mathrm{x}$ approaches a value $a$ if, given any positive number $\varepsilon$, the difference $f(x)-\mathrm{L}$ is less than $\varepsilon$ whenever $x-a$ is less than some number $\delta$ depending on $\varepsilon$. It's like a game: 'You tell me how close you want $f(x)$ to be to L; then I'll tell you how close $x$ has to be to $a$.' Player Epsilon says how near he pleases; then Delta is free to seek his own pleasure. If Delta always has a winning strategy, then $f(x)$ tends to the limit L. (Stewart 1992, pp. 105-106)

Hintikka accepts Stewart's interpretation, except for his use of the expression "as a game"; in his opinion this explanation is not a metaphor but the real way to interpret mathematical statements based on game theory: the description by Stewart is exactly a semantic game, that is a game-theoretical way to explain a mathematical property through an inquiry process.

The LI framework allows us to deal more precisely than Toulmin does with the epistemic relationship between argumentations and classical logical deductions: consequently, we can define a consistent and coherent program for teaching and learning proof in the classroom.

Compared with the Toulmin model (upon which Hintikka comments in this sense), a substantial difference in the inquiry process is that the aim of reasoning in the Hintikka model is to seek the truth and not to convince the opponent, as in the 
Toulmin model. The focus of the former is in investigating the relationships between the mathematical objects, the latter's aim is to convince the opponents that they are wrong.

\subsection{Educating to Rationality Through an Inquiring-Game Activity}

Hintikka's LI model allows the inquiry and the deductive processes to be deeply intertwined through a game-theoretical approach. With this in mind we designed a didactical project with the aim of developing students' argumentation and proof competences, both as specific mathematical competences and as transversal educational competences within a cognitive and epistemic continuity frame.

The project, developed jointly by Arzarello and Soldano in Soldano's (2017) Ph. D. dissertation, proposes a learning trajectory that aims to develop the rationality of the students in accordance with that which is required by the Italian curriculum for Licei, mentioned at the beginning of this chapter (see footnote 3). Unfortunately, it is beyond the scope of this chapter to make a complete exposition of the project and so we limit ourselves to some of its essential aspects to show the didactic consequences of the theoretical framework illustrated above.

Grade 9 students with basic knowledge of elementary geometry were invited to play games which trigger the dynamics within DGEs described by Hintikka, to establish the truth of formulas of the type $\forall x \exists y \mathrm{~S}[x, y]{ }^{8}$ Remember that in the semantic game associated with this formula the falsifier chooses a value $x_{0}$ for $x$, while the verifier is asked to find a value $y_{0}$ for such that $\mathrm{S}\left[x_{0}, y_{0}\right]$ is true. If a winning strategy for the verifier exists, the statement is true. In our game-activities the falsifier, through his/her move, is supposed to drag a dynamic object so that the figure does not show a certain geometric property, while the verifier through his/her move should drag the dynamic object so that the figure shows the property.

Of course, when transposing a theorem into a game, a minimum level of ingenuity is needed to build a situation that is interesting for the pupils. For example, to discover the theorem: "If the median and the angle bisector drawn from the same vertex of a triangle coincide, then the triangle is isosceles", in a dynamic triangle $\mathrm{ABC}$ (vertices built as free points) ${ }^{9}$ a segment $\mathrm{CD}$ and a line $\mathrm{b}$ are robustly constructed $^{10}$ as median and angle bisector from the vertex $\mathrm{C}$ using appropriate GeoGebra tools.

\footnotetext{
${ }^{8}$ Many elementary geometry theorems do not go beyond the complexity of this formula. It is our project to rewrite the theorems in the first book of Euclid's Elements, according to the canons of the LI inside a DGE.

${ }^{9}$ This game was created by an Italian teacher taking inspiration from another game shown by the authors in a conference.

${ }^{10}$ See below the explanation about robust and soft constructions.
} 


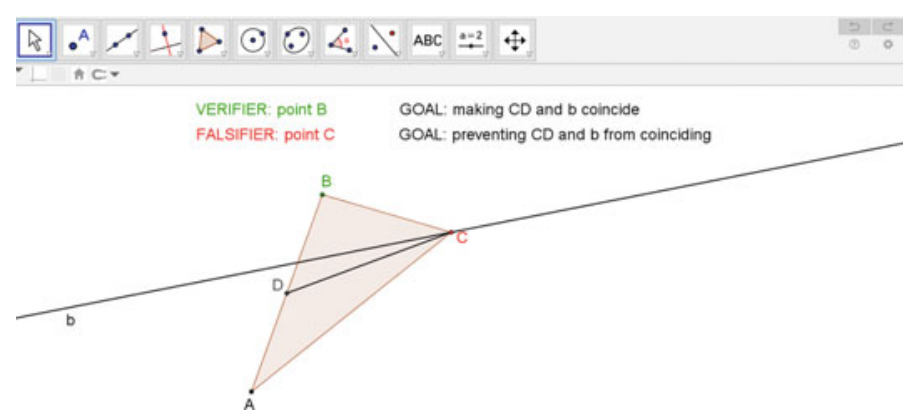

Fig. 10.4 The 'isosceles triangle' game (Link to the game: https://www.geogebra.org/m/ amgmh $3 \mathrm{mf}$ )

Table 10.2 Rules of the 'isosceles triangle' game

Within your pair, establish one verifier who moves the point $\mathbf{B}$ and one falsifier who moves the point $\mathbf{C}$. Each match is made by two moves and the first one is always made by the falsifier.

The goal of the verifier is to make segment $\mathbf{C D}$ and line $\mathbf{b}$ coincide, while the goal of the falsifier is to prevent the verifier from reaching his/her goal.

The winner of the match is the player who reaches the goal at the end of the verifier's move.

After each match go backward with the GeoGebra arrows to reseat the initial configuration. Play some matches and mark an $\mathrm{X}$ in the following table corresponding to the winner of each match.

\begin{tabular}{r|r|c|} 
& Verifier & Falsifier \\
\hline Match 1 & & \\
\hline Match 2 & & \\
\hline Match 3 & & \\
\hline$\ldots$ & &
\end{tabular}

Exchange your roles and play again

\begin{tabular}{r|c|c|} 
& Verifier & Falsifier \\
\hline Match 1 & & \\
\hline Match 2 & & \\
\hline Match 3 & & \\
\hline$\ldots$ & & \\
\hline
\end{tabular}

The verifier's goal is to make the segment $\mathrm{CD}$ coincide with the line b by moving point B (see Fig. 10.4) while the falsifier's goal is preventing the verifier from reaching the goal by moving the point $\mathrm{C}$.

Table 10.2 contains the rules of the game as they were given to the students. Following the rules of the game, the verifier and the falsifier play a semantic game on the following statement: 'For all positions of point $\mathrm{C}$ there exists a position of point $\mathrm{B}$ such that the segment $\mathrm{CD}$ and the line $\mathrm{b}$ coincide'. 
Table 10.3 Worksheet task of the 'isosceles triangle' game

\begin{tabular}{l|l}
\hline (1) & What are $C D$ and $b$ for the triangle ABC? \\
\hline (2) & Which are the properties of the triangles when the verifier reaches his goal? \\
\hline (4) & $\begin{array}{l}\text { From the facts observed during the game and the answers given to the previous questions } \\
\text { formulate a geometric conjecture }\end{array}$ \\
$\begin{array}{l}\text { Using the given connectives, formulate truth statements based on the game. Write as } \\
\text { many as you can. } \\
\text { List of connectives: ... since...; if... then ...; ...if and only if...; } \\
\text { every time that... then ...; ...if...; When ...it happens that...; } \\
\text { In order that... it is necessary that...; In order that... it is sufficient that... }\end{array}$ \\
\hline (5) & Link the discovered statements that have the same meaning \\
\hline
\end{tabular}

From a theoretical point of view the verifier can always win the game by transforming any configuration produced by the falsifier into an isosceles triangle (or a degenerate case).

While playing, students do not know the geometric theorem on which the game is based: the guiding questions contained in the worksheet task (see Table 10.3) are meant to shift students' attention from the game to the geometric properties of the game.

To answer the first two questions, students have to discover that CD is a median, $\mathrm{b}$ an angles bisector and that the triangles produced by the verifier are isosceles triangles. The third question requires students to link the observed and discovered facts so to produce a geometric conjecture. The fourth question provides the students with the mathematical terms for transforming their conjecture in a more strictly logical way. Finally, the last question is meant to focus students' attention on the equivalence of the mathematical statements that are produced.

It is important to remember that each verifier's move produces an example of triangle in which the median and the angle bisector drawn from vertex $\mathrm{C}$ coincide, namely an example of an isosceles triangle, while each falsifier's move produces a non-example of it. Thus, the game's dynamics push students to create logical links between the discovered facts, supporting the transition from inquiring to deductive processes. It should be noted that these logical links refer to the facts observed while accomplishing certain actions in GeoGebra, and not to an axiomatic theory (as happens in standard mathematics): they can help students in their reflections on the relationship between the objects involved in a theorem, catching its meaning and its universal truth.

\subsection{Discussion}

In this section we discuss the meaning of our proposal, expounding some aspects of its theoretical framework and commenting further on its didactical significance. 
The paper has focused on the issue of didactical and epistemological continuity between argumentations and proofs in mathematics learning and is based on two theoretical frameworks, designed by Toulmin and Hintikka respectively.

The Toulmin model has been useful for defining the structure of an argumentation but is inadequate for fully grasping the nature of mathematical statements, for two reasons:

(i) the misleading frame of the jurisprudential context by which it is inspired;

(ii) the limits of syllogistic reasoning, to which Toulmin reduces his analysis, which are structurally incapable of grasping the relational aspects of mathematical properties, in particular its functional features.

The LI model of Hintikka was the theoretical basis on which to overcome such difficulties. To illustrate it, we used the example of Sherlock Holmes' reasoning in Silver Blaze. The episode, according to Hintikka, is paradigmatic to show the philosophy behind the so-called inquiry-based approach to mathematics and science (Harlen 2013):

This idea [of the Logic of Inquiry] is as old as Socrates, and hence older than most of our familiar epistemology and logic. It is the idea of knowledge-seeking by questioning or, more accurately, of all rational knowledge-seeking as implicit or explicit questioning. I am using the phrase 'inquiry as inquiry' to express the idea. For what my leading idea is precisely an assimilation of all rational inquiry in the generic sense of searching for information or knowledge to inquiry in the etymological sense, that is, to a process of querying, or interrogation. (Hintikka 1999, p. ix)

The model of Hintikka offers the following advantages with respect to that of Toulmin:

i. the context: scientific investigation against legal inquiry;

ii. modern logic with respect to syllogistic logic;

iii. a compact dynamic corpus (logic of the investigation/logic of game theory), in which there is a deep dialectic between definitory and strategic rules, which allows the building of new knowledge.

The most important difference is (iii), which deeply distinguishes the two methods. In short, the Toulmin model does not capture in the structural part the innovative aspects theorized in the meta-model, and this makes it incapable of catching the essence of the logic of scientific investigation in its core (it must be said to be true that this it is not Toulmin's goal; he was more interested in everyday argumentation in general).

A relevant aspect of $\mathrm{LI}$ is that it makes the functional interpretation of statements natural through its interpretation within the frame of games, ruled by the dialectics between the strategic principles (which guide the inquiry processes) and the definitive rules (upon which the deductive steps are founded). The functional interpretation based on the notion of strategy has consequences for the semantic arrangement of the model, as we have mentioned, and also reveals the deep links with the questioning method of research as a succession of question-answers, as in 
the Silver Blaze questions. It appears that the statements that structure the argumentations depend on the class of answers that the researcher is able to receive in the course of his research; for this purpose, a purely deductive logic is inadequate:

\begin{abstract}
Most philosophers have apparently assumed that for a scientific inquirer all the rock-bottom answers must be thought of as particular propositions. This assumption has led to the inductivist and to the hypothetico-deductive models of science. In reality, it is nevertheless totally unrealistic, as is illustrated among other things by the possibility of putting questions to nature in the form of experiments. An answer to an experimental question is typically a functional dependence between two variables, which can only be expressed in terms of dependent quantifiers, and hence not a particular proposition. (Hintikka 1999, p. xi)
\end{abstract}

As a consequence of this approach, Hintikka can show an epistemic unity between argumentations and proofs by introducing a new definition of mathematical truth based on the notion of strategies in game theory: a strategy is a rule that tells a player what to do in every imaginable situation that could arise in any hand of the game. To ascertain the truth of a statement $\mathrm{S}$, a semantic game is defined between two players, who assume alternatively the role of verifier and falsifier. In each phase of the game, speaking intuitively, the verifier tries to show that the statement considered at that moment is true and the falsifier tries to prove that it false. It is shown that every semantic game ends after a finite number of moves, with one player winning and the other losing. $S$ is true if there is a winning strategy for the initial verifier (Hintikka and Kulas 1983).

In this way, LI 'reverses', so to say, the standard definition of truth, given by Tarski (1933) and used in all textbooks of logic. In fact, Tarski's definition starts from the condition of truth of the simplest (atomic) sentences and proceeds recursively to the complex ones: for example, to say if $A \& B$ is true one refers to the truth of $\mathrm{A}$ and $\mathrm{B}$. The definition in LI is in the opposite direction: it starts with complex sentences and goes inside them, according to a top-down procedure, which is in accordance with the functional method previously sketched out.

Hintikka's results in the field of logic are the basis of our project, in which elementary geometry theorems are introduced through DGE inquiring-game activities. The aim is to promote learning practices in which inquiring and deductive processes are deeply intertwined with each other. In fact, while playing, students' inquiring processes are guided by strategic choices triggered by typical, maybe implicit, questions that players ask themselves before making a new move: "What can I do in this situation? What is best to do?" To answer these questions, they have to reflect on both the moves that have been made previously and the possible moves that can be made. They activate what is known in the literature as anticipatory thinking (Harel 2001) and backward reasoning (Gómez Chacón 1992; Shachter and Heckerman 1987). Moreover, while answering the questions contained in the worksheet task, students' processes of inquiry are integrated with their deductive ones through the activation of definitory rules.

The previously described Inquiring-Game activity shows that LI can give a solid theoretical basis for setting up didactic projects in which students are introduced to argumentation and proof in an integrated way: in such a way, it can provide also their epistemic unity. 
Fig. 10.5 Non-prototypical configuration of isosceles triangle

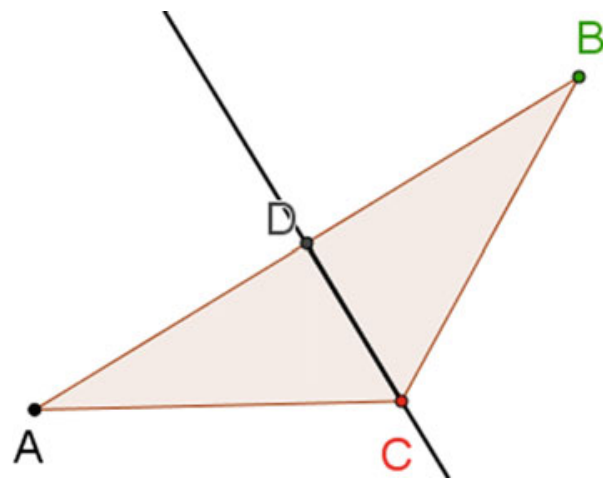

In this regard, LI also constitutes an appropriate epistemic framework for so-called experimental mathematics, ${ }^{11}$ which has become increasingly important in mathematics education because of classroom activities with computers (or more generally with technological devices).

Let us now comment on how the game-activities can influence the processes of student discovery and justification.

The first important thing to note concerns the enlargement of students' personal example space, which is the "set of mathematical objects and construction techniques that a learner has access to as examples of a concept while working on a given task" (Sinclair et al. 2011). The desire to win the game competition drives students to broaden the exploration of the configurations that can be produced with the game, experiencing different examples of the geometric concepts and properties on which the activity is based. By playing, students create not only prototypical configurations of the geometric concept or property, but also non-prototypical and degenerate configurations. In this way, they extend their personal example space. In the problem about the isosceles triangle we observed students struggling with non-prototypical configurations of isosceles triangle such as the case of 'upside-down' isosceles triangles, namely triangles with vertex downside and base upside as shown in Fig. 10.5.

By moving the vertexes, the students make sense of non-prototypical configurations by transforming them into prototypical ones. This investigation is particular

\footnotetext{
${ }^{11}$ Borwein and Kevin (2009) describe the main features of mathematics in this way:

- Gaining insight and intuition.

- Discovering new patterns and relationships.

- Using graphical displays to suggest underlying mathematical principles.

- Testing and especially falsifying conjectures.

- Exploring a possible result to see if it is worth formal proof.

- Suggesting approaches for formal proof.

- Replacing lengthy hand derivations with computer-based derivations.

- Confirming analytically derived results.
} 


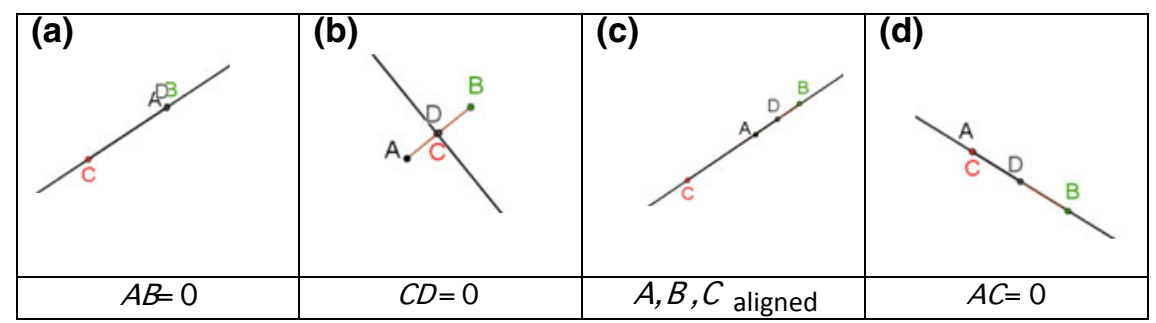

Fig. 10.6 Non-prototypical configuration of isosceles triangle

useful for developing what de Finetti (2015) called the "mathematical way of seeing":

It is especially useful to reflect on examples, to learn and reflect on different examples and to modify them or to build new ones, and, in this way, to be able to better understand and discover what we need to see to overcome a problem. (p. 299, translation by the authors)

During the game phase, students produce degenerate configurations, such as those showed in Fig. 10.6 a, b, c, d. These configurations are a typical product of the competition created by the game: to cause difficulties for the verifier, the falsifier creates configurations in which the verifier can win only by producing degenerate cases. Here there can be perceived a subtle, yet relevant, difference between our model and the jurisprudential one. On one side, the game environment pushes the falsifier to make trouble for the verifier by creating non-prototypical configurations, in which the verifier can win only by producing degenerate cases: this has some similarity with a courtroom dispute between the defence attorney and the prosecutor in a trial and could seem coherent with the Toulmin model.

However, due to the second part of the task (illustrated in Table 10.3), the degenerate cases assume a completely different meaning from the cavils of a lawyer in a trial. In fact, we observed that students propose these configurations again while answering the questions in Table 10.3, and discuss their relationship with the isosceles triangles: some students conceive them as counterexamples that falsify the discovered property, some others conceive them as limit cases, to which it is possible to transform the isosceles triangle. In other words, students start playing the reflective-game (Soldano and Arzarello 2016) in which comparative skill level is insignificant but rather the aim is to discover whether or not the verifier can always win, and, if so, that the geometric properties are still preserved.

The discussion of these configurations moves the attention from the figural to the conceptual aspects of the geometric figures (Fischbein 1993), activating students' critical thinking (Abrami et al. 2015; Toulmin et al. 1984). We can therefore observe empirical evidence for a reduction of the basic gap in these discussions.

The example above shows another interesting aspect of our didactical design: we have just discussed that it is the game environment that promotes the introduction of new elements in students' discussion, namely the degenerate triangles. In a sense, they are similar to the curious incident of the dog that did not bark in the Silver 
Blaze episode. It is an unexpected element introduced in the discourse: C.S. Peirce studied such forms of reasoning and called them abductions. They are typical non-analytical forms of reasoning. Peirce gave different definitions of abduction, some of which are particularly fruitful for mathematical education. One is the so-called syllogistic abduction (Peirce 1960), according to which a Case is drawn from a Rule and a Result. There is a well-known example from Peirce about beans: All the beans from this bag are white (Rule), These beans are white (Result), hence: These beans are probably from this bag (Case). Polya (1971) called it heuristic syllogism. Such an abduction is different from a Deduction that would have the form: the Result is drawn from the Rule and the Case, and it is obviously different from an Induction, which has the form: from a Case and many Results a Rule is drawn. Other forms of abductions are discussed by Magnani (2001, pp. 1718). According to Peirce, an abduction is "the only logical operation which introduces any new ideas" (Peirce 1960) and is essential for every human inquiry, because it is intertwined both with perception and with the general process of invention. In geometry, typically there are theorems that can be proved by considering only the configurations of the objects actually mentioned in the statement of the theorem. In other cases, instead, it is necessary to introduce new objects that are not mentioned in the statement, performing auxiliary constructions. ${ }^{12}$ These distinctions are based on the relevance that Peirce gives to the so-called iconic-diagramatic reasoning or model-based reasoning; therefore, it can be extended to any type of reasoning (on this point see Dörfler 2016). Hence a game approach (particularly within DGS environments) can trigger the production of abductive reasoning, which constitutes again an important aspect of cognitive continuity:

Abductions can be produced within DGS environments, and can bridge the gap between perceptual facts and their theoretical transposition through supporting a structural cognitive unity $[\ldots]$ between the explorative and the proving phase, provided there is a suitable didactic design. (Arzarello et al. 2012, p. 113)

A last remark concerns students' validation and refutation processes. Inside DGE, students validate or refute their conjecture exploiting the dragging test guided by "descending control" (Arzarello et al. 1998, 2002), namely they move dragable or semi-dragable points in order to see whether the geometric configuration keeps the conjectured invariant property. This dragging modality follows what we call the "logic of yes" and leads students to empirically test their conjecture. Within game activities we also observed the activation of another type of logic, the "logic of not" (Arzarello and Sabena 2011), which guides students in the indirect validation of a conjecture, by observing empirically the impossibility of refuting it. ${ }^{13}$ This logic is triggered by the verifier/falsifier dynamics (Soldano et al. 2018). In fact, the falsifier, in order to establish if there is a possibility for her/him to win,

\footnotetext{
${ }^{12}$ Peirce called the two types of proof theoretical and corollarial.

${ }^{13}$ In fact, if there is no counterexample to a statement, the statement is valid: this way of thinking can be in its turn an example of backward reasoning.
} 
generally acts in the following way: he produces a configuration which, provided there is the possibility of winning, would happen with that configuration (it is generally a configuration that forces the verifier to produce a degenerate case); when the falsifier realizes that the verifier wins even in this particular case, this situation leads him/her to establish that the verifier can win in any case. This type of strategy is also activated by students for establishing the truth of the conjectured theorem on which the game is based. This form of backward reasoning is not so spontaneous within a purely deductive framework: it is the game environment which promotes it.

The LI has allowed us to develop a mathematics teaching program that can extend its theoretical epistemic unity/ continuity also to the cognitive and didactic dimensions, in a substantially unitary framework, in order to afford the teaching of proof in the classroom.

There are still many open problems which have emerged from our research, which warrant further study that we intend to develop in the future. Here we list those that seem to us particularly important:

- the transposition of the theorems of elementary geometry and of the elementary analysis within the LI model, using our gamification approach;

- the in-depth study of the links between backward reasoning in game theory and the model described by the LI;

- the analysis of the relationships between the LI and the Lakatos model on conjectures-refutations.

Acknowledgements We wish to thank the teacher Gaetano Di Caprio and the professor Cristina Sabena for their fruitful collaboration in the design of the 'isosceles-triangle' activity.

\section{References}

Abrami, P. C., Bernard, R. M., Borokhovski, E., Waddington, D. I., Wade, C. A., \& Persson, T. (2015). Strategies for teaching students to think critically: A meta-analysis. Review of Educational Research, 85(2), 275-314. https://doi.org/10.3102/0034654314551063.

Arzarello, F., \& Sabena, C. (2011). Semiotic and theoretic control in argumentation and proof activities. Educational Studies in Mathematics, 77(2), 189-206.

Arzarello, F., Micheletti, C., Olivero, F., Robutti, O., \& Paola, D. (1998). A model for analysing the transition to formal proofs in geometry. In A. Olivier \& K. Newstead (Eds.), Proceedings of the $22^{\text {nd }}$ Conference of the International Group for the Psychology of Mathematics Education (Vol. 2, pp. 24-31). Bellville, ZA: Kwik Kopy Printing.

Arzarello, F., Olivero, F., Paola, D., \& Robutti, O. (2002). A cognitive analysis of dragging practises in Cabri environments. ZDM-The International Journal on Mathematics Education, 34(3), 66-72.

Arzarello, F., Bartolini Bussi, M. G.M., Leung, A., Mariotti, M.A., \& Stevenson, I. (2012). Experimental approaches to theoretical thinking: Artefacts and proofs. In G. Hanna \& G. de Villiers (Eds.), Proof and proving in mathematics education (Vol. 15, pp. 97-146). New ICMI studies series. New York: Springer. 
Baccaglini-Frank, A., \& Mariotti, M. A. (2010). Generating conjectures in dynamic geometry: The maintaining dragging model. International Journal of Computers for Mathematical Learning, 15(3), 225-253.

Balacheff, N. (1987). Processus de preuve et situations de validation. Educational Studies in Mathematics, 18(2), 147-176. https://doi.org/10.1007/BF00314724.

Boero, P. (2011). Argumentation and proof: Discussing a "successful" classroom discussion. In M. Pytlak, T. Rowland, \& E. Swoboda (Eds.), Proceedings of 7th Congress of the European Society for Research in Mathematics Education (pp. 120-130). Rszéskow, PL: ERME.

Boero, P., \& Planas, N. (2014). Habermas' construct of rational behavior in mathematics education: New advances and research questions. In Proceedings of the 38th Conference of the International Group for the Psychology of Mathematics Education and the 36th Conference of the North American Chapter of the Psychology of Mathematics Education (Vol. 1, pp. 205235). Vancouver, CND: PME.

Boero, P., Garuti, R., Lemut, E., \& Mariotti, M. A. (1996). Challenging the traditional school approach to theorems: A hypothesis about the cognitive unity of theorems. In L. Puig, \& A. Gutierrez (Eds.), Proceedings of the 20th Conference of the International Group for the Psychology of Mathematics Education (Vol. 2, pp. 113-120). Valencia, ES: Encuademaciones Artesanas.

Boero, P., Douek, N., Morselli, F., \& Pedemonte, B. (2010). Argumentation and proof: A contribution to theoretical perspectives and their classroom implementation. In M. M. F Pinto $\&$ T. F Kawasaki (Eds.), Proceedings of the 34th Conference of the International Group for the Psychology of Mathematics Education (Vol. 1, pp. 179-204). Belo Horizonte, BR.

Börger, E., Grädel, E., \& Gurevich, Y. (1997). The classical decision problem. Universitext. Berlin: Springer.

Borwein, J. M., \& Devlin, K. (2009). The computer as crucible: An introduction to experimental mathematics. Wellesley, MA: A K Peters.

de Finetti, B. (2015). Saper vedere in matematica. In G. Anichini, L. Giacardi, \& E. Luciano (curatori). Bruno de Finetti e l'insegnamento della Matematica dalla Realtà, nella realtà, per la Realtà. Bollettino UMI, Sez A. dicembre 2015. 299-408. New Edition of: Saper vedere in matematica. Loescher (1967).

Dörfler, W. (2016). Signs and their use: Peirce and Wittgenstein. In A. Bikner-Ahsbahs, A. Vohns, R. Bruder, O. Schmitt, \& W. Dörfler (Eds.), Theories in and of mathematics education. ICME-13 topical surveys. Cham: Springer. https://doi.org/10.1007/978-3-319-42589-4_4.

Duval, R. (1991). Structure du raisonnement deductif et apprentissage de la demonstration. Educational Studies in Mathematics, 22(3), 233-261.

Fawcett, H. P. (1938). The nature of proof (1938 Yearbook of the National Council of Teachers of Mathematics). New York, NY: Bureau of Publications, Teachers College, Columbia University.

Fischbein, E. (1993). The theory of figural concepts. Educational Studies in Mathematics, 24(2), $139-162$.

Frege, G. (1879). Begriffschrift: eine der Arithmetischen nachgebildete Formelsprache des reinen Denkens. Halle a/S: L. Nebert Verlag.

Garuti, R., Boero, P., Lemut, E., \& Mariotti, M. A. (1996). Challenging the traditional school approach to theorems. In Proceedings of the 20th International Group for the Psychology of Mathematics Education (Vol. 2, pp. 113-120). Valencia, ES: Encuademaciones Artesanas.

Garuti, R., Boero, P., \& Lemut, E. (1998). Cognitive unity of theorems and difficulty of proof. In Proceedings of the $22^{\text {nd }}$ Conference of the International Group for the Psychology of Mathematics Education (Vol. 2, pp. 345-352). Bellville, ZA: Kwik Kopy Printing.

Gómez Chacón, I. M. (1992). Desarrollo de diversos juegos de estrategia para su utilización en el aula. Epsilon: Revista de la Sociedad Andaluza de Educación Matemática "Thales", 22, 77 88.

Guala, E., \& Boero, P. (2017). Cultural analysis of mathematical content in teacher education: the case of elementary arithmetic theorems. Educational Studies in Mathematics, 96(2), 207-227. https://doi.org/10.1007/s10649-017-9767-2. 
Harel, G. (2001). The development of mathematical induction as a proof scheme: A model for DNR-based instruction. In S. Campbell \& R. Zazkis (Eds.), The learning and teaching of number theory: Research in cognition and instruction (pp. 185-212). Dordrecht, NL: Kluwer Academic Publishers.

Harlen, W. (2013). Inquiry-based learning in science and mathematics. Review of Science, Mathematics and ICT Education, 7(2), 9-33.

Heidegger, M. (1927). Sein und Zeit. Halle: M. Niemeyer. Trans. By Macquarrie, J., \& Robinson, E. (1962). Being and time. New York: Harper \& Row.

Hilbert, D., \& Cohn-Vossen, S. (1932). Anschauliche Geometrie. Berlin: Springer. (English translation: Geometry and the imagination. New York: Chelsea, 1952). 2nd ed. Berlin, 1996.

Hintikka, J. (1997). The place of C.S. Peirce in the history of logical theory. In J. Brunning \& P. Forster (Eds.), The rule of reason, the philosophy of Charles Sanders Peirce (pp. 13-33). Toronto: University of Toronto Press.

Hintikka, J. (1998). The principles of mathematics revisited. Cambridge: Cambridge University Press.

Hintikka, J. (1999). Inquiry as inquiry: A logic of scientific discovery. Dordrecht: Springer.

Hintikka, J., \& Kulas, J. (1983). The game of language: Studies in game-theoretical semantics and its applications. Dordrecht: D. Reidel.

Hintikka, J., \& Sandu, G. (1997). Game theoretical semantics. In van Benthem \& Ter Meulen (Eds.), Handbook of logic and language (pp. 361-410). Amsterdam: Elsevier.

Knipping, C., \& Reid, D. (2015). Reconstructing argumentation structures: A perspective on proving processes in secondary mathematics classroom interactions. In A. Bikner-Ahsbahs, P. Knipping, \& N. Presmeg (Eds.), Approaches to qualitative research in mathematics education (pp. 75-101). Advances in mathematics education. Dordrecht, NL: Springer.

Lolli, G. (2005). QED: Fenomenologia della dimostrazione. Torino: Boringhieri.

Magnani, L. (2001). Abduction, reason, and science: Processes of discovery and explanation. Dordrecht, The Netherlands: Kluwer.

Mariotti, M. A. (2006). Proof and proving in mathematics education. In A. Gutiérrez \& P. Boero (Eds.), Handbook of research on the PME: Past, present and future (pp. 173-204). Rotterdam, NL: Sense.

Pedemonte, B. (2007). How can the relationship between argumentation and proof be analysed? Educational Studies in Mathematics, 66, 23-41.

Peirce, C. S. (1960). Collected papers of Charles Sanders Peirce (CP, Vol. I-VI). In C. Hartshorne \& P. Weiss (Eds.), Cambridge, MA: The Belknap Press of Harvard University Press.

Polya, G. (1971). How to solve it: A new aspect of mathematical method. Princeton, NJ: Princeton University Press.

Rav, Y. (1999). Why do we prove theorems? Philosophia Mathematica, 7, 5-41.

Selden, A., \& Selden, J. (2003). Validations of proofs written as texts: Can undergraduates tell whether an argument proves a theorem? Journal for Research in Mathematics Education, 36 (1), 4-36.

Shachter, R. D., \& Heckerman, D. (1987). Thinking backward for knowledge acquisition. AI Magazine, 8(3), 55-61.

Sinclair, N., Watson, A., Zazkis, R., \& Mason, J. (2011). The structuring of personal example spaces. The Journal of Mathematical Behavior, 30(4), 291-303.

Soldano, C. (2017). Learning with the logic of inquiry. A game-approach within DGE to improve geometric thinking. Unpublished doctoral dissertation, University of Turin.

Soldano, C., \& Arzarello, F. (2016). Learning with touchscreen devices: Game strategies to improve geometric thinking. In K. Larkin \& N. Calder (Eds.), Mathematics Education Research Journal, 28(1), 9-30.

Soldano, C., Luz, Y., Arzarello, F., \& Yerushalmy, M. (2018). Technology-based inquiry in geometry: Semantic games through the lens of variation. Educational studies in mathematics. https://doi.org/10.1007/s10649-018-9841-4.

Stewart, I. (1992). The problems of mathematics (New ed.). New York: Oxford University Press. 
Stylianides, G. J., Stylianides, A. J., \& Weber, K. (2017). Research on the teaching and learning of proof: Taking stock and moving forward. In J. Cai (Ed.), Compendium for research in mathematics education. National Council of Teachers of Mathematics: Reston, VA.

Tarski, A. (1933). The concept of truth in the languages of the deductive sciences (Polish), Prace Towarzystwa Naukowego Warszawskiego, Wydzial III Nauk Matematyczno-Fizycznych 34, Warsaw; reprinted in Zygmunt 1995 (pp. 13-172); expanded English translation in Tarski 1983 [1956] (pp. 152-278).

Thompson, D. R., Senk, S. L., \& Johnson, G. J. (2012). Opportunities to learn reasoning and proof in high school mathematics textbooks. Journal for Research in Mathematics Education, 43, 253-295.

Thurston, W. (1994). On proof and progress in mathematics. Bulletin of the American Mathematical Society, 30(2), 161-177.

Toulmin, S. E. (1958). The uses of argument. Cambridge, UK: Cambridge University Press.

Toulmin, S. E. (1974). Rationality and scientific discovery. Boston Studies in the Philosophy of Science, 20, 387-406.

Toulmin, S. E. (1975). Gli usi dell'argomentazione. Torino, IT: Rosemberg \& Sellier (traduzione di Toulmin 1958).

Toulmin, S. E., Rieke, R., \& Janik, A. (1984). An introduction to reasoning. New York: Macmillan.

Zarębski, T. (2009). Toulmin's model of argument and the "logic" of scientific discovery. Studies in Logic, Grammar and Rhetoric, 16(29), 267-283.

Open Access This chapter is licensed under the terms of the Creative Commons Attribution 4.0 International License (http://creativecommons.org/licenses/by/4.0/), which permits use, sharing, adaptation, distribution and reproduction in any medium or format, as long as you give appropriate credit to the original author(s) and the source, provide a link to the Creative Commons license and indicate if changes were made.

The images or other third party material in this chapter are included in the chapter's Creative Commons license, unless indicated otherwise in a credit line to the material. If material is not included in the chapter's Creative Commons license and your intended use is not permitted by statutory regulation or exceeds the permitted use, you will need to obtain permission directly from the copyright holder. 